\title{
Predictors of Availability in Home Life Context-Mediated Communication
}

\author{
Kristine S. Nagel, James M. Hudson, Gregory D. Abowd \\ GVU, College of Computing \\ Georgia Institute of Technology, Atlanta, GA \\ (404) 894-3152 \\ $\{$ kris, jhudson, abowd\}@cc.gatech.edu
}

\begin{abstract}
A number of studies have explored issues of interruption and availability in workplace environments, but few have examined how attitudes toward availability play out in home life. In this paper, we begin to explore factors in the home that might be useful for signaling availability to close friends and family. In particular, we use the Experience Sampling Method (ESM) to measure subjects' current activities and self-reported availability to interruption. Based on follow-up interviews, we develop a number of hypotheses that we test through a hierarchical linear regression analysis. Results indicate that individual differences, certain home locations, and leisure activities play an important role in determining patterns of availability. This study has implications for the development of CSCW systems with automatic sensing of activity to deal with interruption and activity recognition both inside and out of the home.
\end{abstract}

\section{Categories and Subject Descriptors}

J.4 [Computer Applications]: Social And Behavioral Sciences - sociology, psychology. K.4.3 [Computing Milieux]: Computers And Society - computer-supported collaborative work.

\section{General Terms}

Human Factors, Design.

Keywords

Interruption, home, context-mediated communication.

\section{INTRODUCTION}

When we want to communicate with a family member or a close friend, we consider calling or going in-person, but it is often difficult to know when it is a good time to interrupt. Some households rely upon an answering machine or service like caller id to screen incoming calls, but these techniques only serve the interrupted party, not the initiator. We envision a world of context-mediated communication, in which knowledge of availability (in some appropriate form) is made known to trusted parties prior to any communication act. Just as answering machines and caller id allow potential recipients to make decisions on how to filter interruptions, we want to provide mechanisms that allow a caller to preview activity

Permission to make digital or hard copies of all or part of this work for personal or classroom use is granted without fee provided that copies are not made or distributed for profit or commercial advantage and that copies bear this notice and the full citation on the first page. To copy otherwise, or republish, to post on servers or to redistribute to lists, requires prior specific permission and/or a fee.

CSCW'04, November 6-10, 2004, Chicago, Illinois, USA.

Copyright 2004 ACM 1-58113-810-5/04/0011 ...\$5.00. status of an individual in advance of the call. Although it is easy to think of how such context might support appropriate social protocols, it is not clear what kind of contextual cues could be accurately and acceptably extracted from a home to communicate availability.

Providing context-mediated communication services requires knowledge of factors predicting a person's availability for interruption. In office settings, studies indicate that one is least accessible when any human speech is detected prior to the interruption [14]. Patterns of email access and other desktop computing interactions also predict presence in a workplace and may be used to infer communication times and modes [2]. Individuals also use mental boundaries on their various roles to manage accessibility; these boundaries are enacted through visible artifacts and behaviors, often associated with particular locations and times [21].

Do such patterns of predictable interruptibility exist in the home? There are several research initiatives attempting to enable homes with awareness of inhabitants' location and activities $[15,20]$, but these do not yet provide information on which activities and locations are useful in predicting household members' amenability to interruption.

To determine if there are any externally observable factors in home life that correlate with availability, we use an Experience Sampling Method (ESM) study on PDAs that asks our subjects for both situation data and availability at the moment. Our study examines family members with rich communication networks including spouses, children, family, and friends. Specifically, we examine married couples with young children in the home. Although this is a relatively narrow demographic, it is representative of family home life, with demands for attention from simultaneous activities and frequent interruptions.

Below, we describe our ESM study and analysis of the data collected, both quantitative and qualitative. We discuss the results of a regression analysis and some implications for the design of inter-home context-mediated communication services. We conclude by discussing challenges that arise in developing sensors for detecting activity in home settings and providing appropriate accessibility to family members.

\section{INTERRUPTIONS AND HOME LIFE}

The study of workplace interruptions has extended cognitive psychology experiments and empirical studies of managers' availability. Machine learning techniques have been used to adapt attention cues to interruption signals applied to humancomputer interaction [12]. McFarlane has investigated the effects of a four types of coordination when issuing an 
interruption from the computer interface [18]. Empirical studies of office interruptions have also shown correlations between environmental factors and availability. In one study employing "Wizard of Oz" techniques to simulate a variety of sensors gathering data in an office, anyone talking was a strong predictor of availability (78\%) [14]. Other studies of managers used sampling methods to gather current context and availability, highlighting the tension in managing interruptions $[13,22]$. Each of these office-based studies sought to determine availability from observable phenomena, rather than invisible cognitive states.

Patterns of availability also help synchronize communication and manage work activities. Medical workers use temporal patterns within the hospital to coordinate work and information [26] and office workers may use rhythms of computer interaction and email access to predict availability of colleagues at geographically remote work locations [2]. Within the home, there is an expectation of more control over one's social accessibility; temporal boundaries define one's "niche of inaccessibility" [33]. Routine behaviors are frequently seen in home life, minimizing the mental cost of when and what to do, ordering the chaos of competing roles in the home [21]. Routines often focus on the communication centers of the home [7]. Just as temporal rhythms exist in work practice, empirical and qualitative data portray time-based routines at home.

The Casablanca study showed facilitating interpersonal relationships is a strong motivator for home-based technology [11]. However, the telephone is often equated with interruption, at home and the office [18]. To minimize intrusion, Milewski and Smith augmented a workplace telephone system to provide the caller with self-declared availability status of the callee [19]. Unfortunately, humans are not reliable at updating their status, so such systems are not useful. Longitudinal home telephone use studies have shown the callee expects the caller to know their patterns of availability [16]. We are examining how technology made aware of rhythms and availability predictors may enable humans to determine better times to initiate conversation between family members' homes. If environmental sensors could detect the predictors of availability and automatically update status, then such a system may prove to be effective in managing phone interruptions in the home.

\section{METHOD \\ 3.1 Studying Home Life}

It is often difficult for researchers studying home life to get at the richness and complexity of experiences inside the home. Laboratory studies allow researchers to carefully look at variables of interest, but they necessarily cannot account for the complex social systems [4] that typically interest home life researchers [7]. Ethnographic studies allow researchers greater access to this complexity [9], but require significant investments of researchers' time [10]. As a further complication, home life research often seeks to study time that is considered fairly private by research subjects $[11,13]$. Not surprisingly, research subjects who allow for ethnographic observation during home life might not be typical!
To get around these concerns, researchers sometimes use clinical style interviews to probe subjects to reflect on their home lives. Through interviews, subjects can provide rich details about the complexities of their home lives without sacrificing privacy [27]. Unfortunately, memory is notoriously fallible and subjects often cannot accurately recall how they spend their time [10]. Even if memory were perfect, however, interview responses are subject to a number of response biases [32]. A research subject can and often will edit his or her response to reflect either what $\mathrm{s} / \mathrm{he}$ believes the interviewer wants to hear or prevailing social norms.

Researchers often attempt to deal with the fallibility of memory by turning to a variety of diary-based methods. In self-reported diary studies $[8,23]$, research subjects fill out a diary of their activities after the fact-typically at the end of each day. In doing so, this method asks subjects to reflect on activities soon after they occur. This significantly improves recall ability [10]. Nonetheless, time estimates from self-reported diary studies are often flawed since individuals tend to be poor judges of time when reflecting on their daily activities [17].

The Experience Sampling Method (ESM) was designed as a way to obtain better estimates of how people really spend their time [17]. In this method, subjects wear some form of a pager that randomly goes off during the day. When the pager goes off, the subject fills out a survey-either on paper [8, 17] or, more recently, on the device itself $[5,13,15]$. The survey asks participants to answer questions about their attitudes and activities only at the moment the pager went off. As such, this reduces the distortions observed in methods requiring greater recall and reflection. Because ESM samples subjects at random times, it can provide a fairly good overview of major activities that people engage in. At the same time, results from ESM studies tend to miss rarely occurring events and transitions between events.

While no research method is perfectly reliable, we chose to use a combination of ESM and interviews as a way of dealing with the complexity of home life. Through this combination of methods, we aimed to achieve a balance between the richness of data that an interview provides and the somewhat more objective data that ESM provides.

Over a period of four weeks, we asked eight subjects to participate in an ESM study for one week each. Based on the ESM results, we generated individual availability profiles to help structure follow-up interviews. In these interviews, we asked each subject to review and reflect upon the accuracy of their individual profile. Using grounded theory [6], we generated a number of hypotheses about the predictors of availability based on our interview data. We tested these hypotheses through a regression analysis on our ESM data. Further examination of interview data helped us interpret the findings from our statistical analysis.

In this section, we describe our study design in more detail. Then, we turn our attention to the results and their implications for the design of CSCW systems inside and outside of the home. 
Table 1. Sample Survey Questions

\begin{tabular}{|c|c|c|c|}
\hline $\begin{array}{l}\text { 1. } \text { Right now I am ... } \\
\text { - by myself } \\
\text { - } \quad \text { with one other person } \\
\text { - } \quad \text { with } 2 \text { or more persons }\end{array}$ & $\begin{array}{ll}\text { 2. } & \text { My location is at ... } \\
\text { - } & \text { Home } \\
\text { - } & \text { Work } \\
\text { - } & \text { a Store } \\
\text { - } & \text { a Recreation site } \\
\text { - } & \text { in a Car } \\
\text { - } & \text { Other location }\end{array}$ & $\begin{array}{l}\text { 3.My current LEISURE } \\
\text { activities include ... } \\
\text { - } \quad \text { Watching TV or Movie } \\
\text { - } \quad \text { Reading } \\
\text { - } \quad \text { Game playing } \\
\text { - } \quad \text { Sleeping or Napping } \\
\text { - } \quad \text { Family gathering } \\
\text { - } \quad \text { Other }\end{array}$ & $\begin{array}{l}\text { 7. Would this be a good time for an } \\
\text { adult family member to get your help } \\
\text { with an activity or task they consider } \\
\text { urgent? } \\
\text { - No, not at all } \\
\text { - Not now, maybe in a few minutes } \\
\text { - Yes, for just a moment } \\
\text { - Yes, for however long }\end{array}$ \\
\hline
\end{tabular}

\subsection{ESM Study Method}

We gave each participant a small personal digital assistant (PDA) to carry with them during their home life for one week. At random intervals, the PDA interrupted the user with an alarm, and presented a brief survey to complete. The interruptions were scheduled to randomly occur once within each 30-minute interval. The survey consisted of ten questions modeled on those of Hudson et al. [13], and could be answered by an experienced participant in less than one minute. The survey asked participants questions in the following general categories:

- "Are you alone or with others right now?"

- "Where are you?"

- "What are you doing right now?"

- $\quad$ "How would you feel about someone interrupting you right now?"

Samples of relevant questions are shown in Table 1 . We designed the questions to provide fine-grained responses to these questions. For example, when location response was "home", the next question requested the room. There were questions to cover the four categories of activities, derived from Venkatesh's technology use within the home [31]: communication, food related, household tasks, and leisure. Within each of these there were four to five specific activities and "other", where any combination or none could be selected, as fit the current activities. Two questions determined availability to another adult family member:

1. Would this be a good time for an adult family member to get your help with an activity or task they consider urgent?

2. Would this be a good time for an adult family member to catch up on today's events with you?

Participants expected the probes and alarms to be annoying, but all completed the one-week study.

We used Sony Clies running iESP ${ }^{1}$ to conduct this study, with the exception of one participant using her own PalmV. The iESP software is an open-source package for managing ESM on PalmOS PDAs. We chose the Clie for its form factor and compatible PalmOS version. The Clie is relatively small and light (easy to keep with you), and has a stiff screen cover, that prevents accidental response to a survey.

\footnotetext{
1 Intel Experience Sampling Program, iESP, http://seattleweb.intel-research.net/projects/ESM/.
}

When each subject received the device, s/he completed a short survey of demographic information and received training in iESP on the appropriate PDA. The eight subjects each participated for one week, keeping the device with them during individually designated "home life" hours. Two participants were home all day with children, and used the same time range for weekday and weekend, approximately 9:00 am to 10:00 pm. Weekday start times for the other subjects ranged from 5:00 pm to 6:30 pm with ending times between 9:00 pm and 11:30 pm. Weekend start times were between 8:00 am and 1:00 pm with ending times the same. The pre-study training session provided an opportunity to ensure consistent interpretation of terms used in each question of the survey. Rooms within each person's home were mapped onto the list of rooms presented.

If a survey was not answered within a specified time frame, then a "missed survey" was recorded at that date and time. Each question also had a time-out interval. This insured the data was recorded close to the time of the alarm and not recalled later. The completion rate of $85 \%$ (644 of 766 surveys administered) is comparable to similar studies $[13,17]$. At the follow-up interview, researchers shared a profile of the participant's home activity, clarified comments entered, and probed for why surveys were missed. We offered a token reward of two dollars per day, maximum of fourteen dollars paid at the post-study interview.

\subsection{Subjects}

The study involved participants from the community and university. In particular, we focused on adults living in a family home with their significant other and at least one dependent child. There were two parents who spent their day at home with the child, one of whom was a graduate student who worked outside the home one or two days a week. Two other volunteers were also graduate students, three were professors from different colleges, and one was self-employed working from a home office. Of those invited, two declined to participate; one did not have time and one did not want an interrupting device in their home.

Our eight married participants represented six families; we had two couples in our study, where each person carried a device. Four subjects were female and four were male. Ages ranged from the 20's to the 50's, and averaged in the 30's. There were four single child homes, one home with two children, and one home with three children. The children ranged in age from six months to nineteen years old. One participant was of European background, two were from South America and the remaining were North American. This is an artifact of the university 
community, not an intentional design to examine cultural communication differences. Each of these international subjects have lived in America for more than a year. All of the participants used multiple communication devices and technologies, and had at some time owned a cell phone. Many of the personal communication partners listed were in different time zones and overseas.

\section{RESULTS AND DISCUSSION 4.1 Individual Profiles and Interviews}

To structure our interviews, we created individual profiles for each subject based on their responses to the ESM portion of our study. In addition to descriptive statistics, these profiles contained information about the simple correlations between availability and a number of other variables, such as number of people present, location within the home, engagement in conversation and time.

We used these individual availability profiles both to validate the data collected and to refine our hypotheses for aggregate data analysis. We asked each participant how well the various correlations matched their intuition of availability. We also asked about other factors that might be useful in determining the availability. In general, our subjects felt that these individual profiles accurately represented their availability to interruption.

Comments made by our subjects indicated that individual differences might play an important role in determining availability:

"[I am] by myself when [I] need to be by myself, not by accident."

"By myself, ... felt like [I was] more available for
interruption."

Individuals also often spoke of location in contradictory terms. Sometimes, one location might indicate availability. At others, it might indicate unavailability. Instead, the important predictor of availability seemed to be activity, as comments about the kitchen were usually qualified with phrases like "in the middle of cooking" or "while helping with homework." Nonetheless, the interviews seemed to indicate the kitchen holds special status because of its role in social activities, such as preparing meals.

Although the literature would suggest that face-to-face conversation might be a good predictor of (un)availability [1], interview data indicate that face-to-face conversation might be more nuanced than that. For some subjects, availability during face-to-face conversation varied depending on the interlocutor. For others, availability had more to do with the larger activity than face-to-face conversation itself. One individual commented that family dinner conversations take precedence:

"My guess is... when I was having face-to-face conversation and I said I was available, it was not related to a meal."

To further complicate the matter, family members in a home often conceive of interaction as "face-to-face" even if they are in separate rooms. One specifically cited talking between the living room and kitchen, where they are not visible to the other, yet they are engaged in conversation.
Finally, routines emerged as important phenomena in home life, as seen in other home studies [7]. All of our subjects raised the issue of rhythms, especially relating to the normal bedtime preparations for young children. The issue of time rhythms is discussed in more detail below.

Before moving on to examine the patterns of data found in our ESM results we also looked at the aggregate data across all subjects to determine additional features of interest. Communication (36\%) and leisure activities $(29 \%)$ dominated. In $60 \%$ of the surveys there were multiple simultaneous activities, similar to reports in time use studies [29]. Over $80 \%$ of the surveys were answered while in the home, over half of these were equally split between the kitchen and living room. The individual interviews and features within aggregate data influenced our regression analysis.

\subsection{Hierarchical Logistic Regression Results}

Ultimately, we are interested in determining a set of externally measurable variables that help predict an individual's availability for conversation during home life. We choose to conduct a hierarchical logistic regression on availability in our aggregate ESM data as a way of identifying variables that seemed to hold promise. We choose this analysis because statistical regression analysis specifically asks questions about the relative importance of a set of variables in predicting an outcome. Each survey asked participants to indicate availability, so we were able to use reported information about the individual's state to attempt to predict answers for availability. Logistic regression simply refers to the fact that our predicted outcome (availability) is a binary variable. To obtain this availablility variable, we used a dummy coding scheme and gave "available" survey responses a value of one and "not-available" survey responses a value of zero.

Hierarchical regression allows us to enter sets of variables in multiple steps. Each step asks whether the new set of variables allows us better prediction ability over and above the previous set of variables. In other words, each step accounts for a certain amount of the variability observed in our dependent measure (availability). Subsequent steps ask whether or not the new variables explain any of the remaining variance. While ordering of these steps is debatable, we have tried to follow standard psychological practice of moving from more distal predictors of availability (e.g., individual differences) to more proximal ones (e.g., current activities). Note that ordering does not affect the final outcome, only the interpretation at each step. Since we intended this as an exploratory analysis, we have chosen to use rather loose measures of significance. Therefore, we refer to $\alpha<0.1$ as significant. We refer to $\alpha<$ 0.2 as marginally significant. With these significance ranges, we cannot make definitive statements about our data. Rather, we hope to provide indicators of promising areas for future research. Results are listed in Table 2.

In the first stage of our regression analysis, we asked whether or not individual differences predict availability. Because it does not statistically make sense to represent individuals as rational numbers, we needed to generate a number of orthogonal contrasts. For the purposes of this study, significant values for orthogonal contrasts indicate that some individual 
Table 2. Regression equation variable values

\begin{tabular}{|c|c|c|c|c|}
\hline & Variables & B Coefficient & Wald Statistic $^{1}$ & $\begin{array}{l}\text { Significance } \\
\text { (p-value) }\end{array}$ \\
\hline \multirow{7}{*}{$\begin{array}{l}\text { Step } 1 \\
\text { Subject }\end{array}$} & \multirow{7}{*}{$\begin{array}{l}\text { Individual Differences }(n=8) \\
\text { Computed as } 7 \text { orthogonal contrasts }\end{array}$} & .451 & 1.822 & $.177 *$ \\
\hline & & .165 & .554 & .457 \\
\hline & & .671 & 3.960 & $.047 * *$ \\
\hline & & .857 & 14.185 & $.000 * *$ \\
\hline & & -.739 & 12.839 & $.000 * *$ \\
\hline & & .361 & 1.363 & .243 \\
\hline & & -1.663 & 10.125 & $.001 * *$ \\
\hline \multirow{6}{*}{$\begin{array}{l}\text { Step } 2 \\
\text { Location } \\
\text { Time }\end{array}$} & Living areas vs. kitchen & -1.395 & 9.074 & $.003 * *$ \\
\hline & Out of home vs. kitchen & -1.426 & 9.766 & $.002 * *$ \\
\hline & Others bedroom vs. kitchen & -2.547 & 15.734 & $.000 * *$ \\
\hline & Other rooms vs. kitchen & -1.247 & 8.818 & $.003 * *$ \\
\hline & Time of day & -.001 & 1.382 & .240 \\
\hline & Weekend Day & .579 & 1.799 & $.180^{*}$ \\
\hline \multirow{3}{*}{$\begin{array}{l}\text { Step } 3 \\
\text { Companionship }\end{array}$} & Alone vs. with others & -.372 & 2.014 & $.156^{*}$ \\
\hline & With one other vs. two or more & .204 & 1.494 & .222 \\
\hline & One adult with child(ren) & -.190 & .313 & .576 \\
\hline \multirow{15}{*}{$\begin{array}{l}\text { Step } 4 \\
\text { Activities }\end{array}$} & Face-to-face conversation & -.772 & 5.639 & $.018^{* *}$ \\
\hline & Telephone call & -.373 & .457 & .499 \\
\hline & Email & 1.846 & 2.618 & $.106^{*}$ \\
\hline & Eating & -.238 & .455 & .500 \\
\hline & Food preparation & -.016 & .001 & .973 \\
\hline & Meal clean-up & -.187 & .126 & .722 \\
\hline & Other food activities & -.898 & 1.702 & $.192 *$ \\
\hline & Watching TV or movie & 1.237 & 9.573 & $.002 * *$ \\
\hline & Reading & .761 & 2.422 & $.120^{*}$ \\
\hline & Game playing & 1.994 & 9.390 & $.002 * *$ \\
\hline & Family gathering & .547 & .527 & .468 \\
\hline & Other leisure & .879 & 6.419 & $.011 * *$ \\
\hline & Laundry/Housekeeping & .769 & 2.402 & $.121 *$ \\
\hline & Personal/Family info management & 1.827 & 4.546 & $.033 * *$ \\
\hline & Other household tasks & .424 & 1.136 & .287 \\
\hline Step 5 Bedtime & Bedtime routine for children & -.165 & .017 & .898 \\
\hline
\end{tabular}

* Marginally Significant at $\alpha<0.2 * *$ Significant at $\alpha<0.1$

NOTE: Values above indicate the final values in our regression analysis, not the intermediate values at each step. $\Delta \mathrm{R}^{2}$ was significant at $\alpha<0.05$ for steps 1,2 , and 4 . For step $3, \Delta \mathrm{R}^{2}$ change was marginally significant $(\mathrm{p}=0.053$ ). Step 5 was not significant $(\mathrm{p}=0.898)$. Positive $\mathrm{B}$-coefficients indicate that individuals are more available for interruption and negative $\mathrm{B}$ coefficients indicate less availability. Full statistical analysis is available from the authors upon request.

differences exist. The exact meaning behind each of these contrasts is less important. Results from this step indicate that a number of individual differences exist. We explore this finding in more detail in the next section of the paper.

In the second step of our regression analysis, we examined the predictive power of location, time, and day of the week over and above the observed effects of individual differences. We examined five different locations:

1. Living room, including the family room

2. Kitchen

3. Someone else's bedroom (usually a child)

4. Other rooms in the home, including patio and yard

5. Outside of the home
Once again, location is a variable that cannot be represented as a rational number. When faced with these nominal variables, we can code them in many ways (e.g., orthogonal coding, dummy coding, effects coding). Each coding scheme lends itself to different types of interpretation. While none of these schemes seemed ideal for coding this variable, dummy contrasts provide the most readily interpretable results. In dummy contrasts, one value of the variable is chosen as a baseline against which we compare all other values. We chose to use the kitchen as our baseline measures because many subjects suggested that the kitchen tended to indicate availability. Significance for this set of variables indicates that availability in a given location is different from availability in the kitchen. 
The time variable is the number of minutes elapsed in the day and weekend is binary indicator of weekday vs. weekend.

Results from this step of our analysis indicate that interruption in the kitchen is more acceptable than other rooms in the house. Interruption is particularly bad in someone else's (presumably a child's) bedroom. Time and day do not appear to matter much, but this may be a limitation of linear regression analysis, which is discussed below.

In the third step, we added variables measuring companionship and the presence of children. Because of how our survey was structured, we represented companionship as two orthogonal contrasts:

1. Companion Contrast 1: Is there a difference in availability when a subject is alone vs. when s/he is with other people?

2. Companion Contrast 2: Is there a difference in availability when a subject is with one person vs. when s/he is with more than one person?

In addition to companionship, we computed a new binary variable to indicate situations when a subject is the only adult with his/her child(ren). Results indicate that our first companion contrast is marginally significant. In other words, it does not seem to matter how many people are around or if any of them are children.

In the fourth step of our analysis, we asked whether selfreported activity is useful in predicting availability over and above the measures already examined. In this step, we included fifteen binary, self-reported activity variables. Of these, five were significantly useful for predicting availability: talking face-to-face, watching TV or movies, playing games, performing other leisure activities, and managing personal information. Other food activities, sending and reading email, reading more generally, and housekeeping are marginally significant. Since this research is exploratory and uses loose significance levels, further research is needed to determine the practical significance of these variables. Rather than attempting to definitively identify predictors of availability in the home, the analysis seeks to highlight seemingly important predictors so that future research can begin with a more limited set of variables.

Based on our interview results, we attempted to examine childrens' bedtime routines in the fifth and final step of our regression analysis. To do this, we constructed a binary variable representing when an adult was alone with a child in either the bathroom or the child's bedroom engaged in specific activities (face-to-face conversation or other household task, for bathing child) between 7:30 pm and 9:30 pm. Results indicate that this added no predictive power above our previous variables. As we discuss in more detail below, routines seem to play an important role that is not adequately captured by the ESM data.

Table 2 summarizes the variables added at each step and their final significance levels. This statistical model shows significant effects for individual differences, locations, and a variety of activities. Note that regression produces a statistical model that is basically an additive linear equation. For example, our model tells us that knowing someone is in the living room helps us predict availability. It also tells us that knowing when someone is playing games helps us predict availability. This tells us that we'll have even better predictive power if we know that individuals are both in the living room and playing games. In the next section, we explore these factors in more detail before describing the implications of this work.

\section{DISCUSSION}

Through our interview data and the statistical analysis, a number of interesting factors arose. Individual differences play an important role in determining patterns of availability. Location provides some useful information for determining availability, but certain spaces seem more important than others. Leisure activities seem to be more powerful predictors of availability than other activities. Time also appears to play an important role, but this needs further exploration. Below, we explore each of these in more detail.

\subsection{Individual Differences Matter}

The regression analysis and interview data portray varying individual inclinations toward availability. For example, three of our subjects answered that they were available approximately $70 \%-80 \%$ of the time. Two subjects were only available $40 \%-50 \%$ of the time. (The remaining three subjects were available approximately $65 \%$ of the time.)

Not only were some subjects more inclined to interruption than others, individuals tended to treat some similar situations differently. For example, some subjects stated that they were not available when friends or guests were over:

"[I wasn't available] with the people there... or if other people we had scheduled to come by for meals."

Others indicated that this was a great time for interruption:

"And the friends were there. And because it was a birthday party, I wouldn't have minded people calling. “

Likewise, individuals treated availability differently when preparing food:

"[I wasn't available] we were in the middle of cooking"

"You know, I'm available when I'm cooking dinner and I'm not as available when I'm eating dinner."

Since many leisure activities (e.g., watching TV or playing games) turned out to be significant predictors of availability, we were somewhat surprised to see that reading only had marginal significance as a predictor. This may have to do with individual differences. While some individuals are available while reading, others indicated that this is a terrible time for interruption:

"Basically if I'm reading a book, I just don't want to be bothered."

This is in keeping with Janice Radway's findings in Reading the Romance [25]. In this work, Radway described how a group of stay-at-home mothers used romance novels as a way of carving out time for themselves. If Radway's findings can be generalized to other genres, it's not surprising that we might find differing levels of availability during reading. 
While we did not design this study to examine couples, we did have two couples participate. While exploring the contrasts between individuals, we noticed some correlation between members of each couple. This suggests that individual differences may be reduced within family units. Further research is necessary to explore this hypothesis.

\subsection{Some Locations Matter}

The kitchen figured prominently in both the interviews and the survey data, usually correlated to availability. However, in some homes, the kitchen as a physical room comprises multiple activity areas. For example, one might be available in the food preparation area of the kitchen, but not available when assisting a child with homework at the table. Subjects often pointed to open and fluid home designs as ambiguous indicators of availability.

However, unlike other rooms, bedrooms seem to be more consistently viewed as homogeneous availability indicators:

"Yeah, now see when I was in others bedroom, that's usually when I'm putting the kids to bed and I'm pretty much not available then. If I'm in my bedroom, I'm more likely to be relaxing and so I'm more available."

The Other's Bedroom contrast is significant $(\mathrm{p}<.001)$ and negatively correlated $(\mathrm{B}=-2.547)$ to availability. Interviews show this is most often the child's room, where the parent could be attending to, playing with, or reading with the child.

The living room, family room and den are considered together in the living areas contrast and are of equal significance to the contrast composed of all other rooms within the home. The out of home contrast includes the car, recreation sites, and homes of other family and friends. While each is a significant indicator as compared to the kitchen, they are similarly correlated. Some room location may be useful in determining where to deploy sensing relative to providing the high correlation to availability, or with concerns for privacy or safety.

\subsection{Activities and Availability}

While our data highlights differences in availability between office workers and family members at home, there is some consistency on shared activity factors. For instance, the most prominent activity in our data is face-to-face conversation (46\% of the surveys). It is significantly $(\mathrm{p}=.018)$ and negatively $(\mathrm{B}$ $=-.772$ ) correlated to availability. In other words, engaging in conversation is likely to make individuals less available for interruption. This is similar to Hudson et al.'s office-based study finding anyone speaking in the office predicts uninterruptability $75 \%$ of the time [14]. Although Hudson et al.'s tuned model predicts unavailability with $90 \%$ accuracy, our model is a stronger predictor for availability. It is possible that this result may stem from the propensity of our data towards availability ${ }^{2}$; overall our participants were available

${ }^{2}$ Research in professional office settings, however, indicates that office workers view handling interruption as an important part of their jobs [13]. Regardless, studies seem to do better at predicting uninterruptible times in the office and available times at home.
$67 \%$ of the times they were surveyed. We would expect this number to decrease if missed surveys were accurately coded and included. Participants indicate they were most often not available when a survey was missed. The social construction of conversation at home versus in the office may explain this difference:

"For most of the time I was in face-to-face conversation, the conversation was not so important that I would not allow myself to be interrupted."

Subjects spoke of being more interruptible when they were in conversation. They indicated that they were more amenable to conversation when already engaged in one. Many subjects characterized home conversation as short and sporadic. This interaction style naturally seems to lend itself to interruption.

Leisure activities accounted for $29 \%$ of all activities reported. Watching TV or a movie $(\mathrm{p}=.002, \mathrm{~B}=1.237)$, game playing $(\mathrm{p}=.002, \mathrm{~B}=1.994)$, and other leisure activities (e.g., listening to music) $(\mathrm{p}=.011, \mathrm{~B}=.879)$ were significantly correlated to availability. Leisure activities were frequently mentioned:

“... [I] think it accurately reflects what's going on. Clearly I don't have that many TV shows that I don't answer the phone for! Only one or two."

Reading is marginally significant $(\mathrm{p}=.120)$ and positively correlated $(\mathrm{B}=.761)$.

Note that we only asked about availability for close friends and family. We do not address the tensions of controlling workoriented interruptions to home life [13]. Also, there are specific instances of leisure activities where participants talked about not being available - when a PC game cannot pause or when a certain "soap opera" is broadcast.

\subsection{Relevance of Time-based Rhythms}

Based on our interview data, it seems that time plays an important role in interpreting availability. Not surprisingly, though, our regression analysis indicated that time was not a significant predictor of availability. Regression analysis techniques, such as the one employed here, assume a linear relationship between predictors and the independent variable. In other words, this analysis technique presumed that availability either linearly increased or linearly decreased as it got later in the evening.

Our interview data, however, suggests that time does not play a linear function for predicting availability. Instead, time tends to follow certain rhythms, similar to those described in [2] and [13]. In particular, dinner and bedtime routines seem to affect availability. As one participant commented:

"We usually eat at 7:00. [My child] usually goes to bed between 8:30 and 9:00. So those are activities that would have precluded my availability."

Based on our interview data, there seem to be more complex time rhythms as well that our ESM data was unable to assess. Since our ESM study only covered one week for each subject, we were not able to observe events that separate the weekend from weekdays nor were we able to observe events that reoccur on weekly or monthly schedules. 
At the same time, the ESM study did not allow us to observe the transition events that interviews indicated were important. We do not know how frequently or when location changed, or whether our probes simply occurred at a transitory location such as walking through the dining room to the kitchen. There are also transition activities, such as "walking out the door" or arriving home, where participants were not available for that frame of activities.

\section{IMPLICATIONS FOR CSCW}

In some ways, our results replicate similar studies of interruption and time use in the workplace $[13,14,24,28]$. In many ways, however, these findings indicate that individuals tend to have strikingly different predictors of availability in personal and professional life. Studies of workplace environments have developed metrics that work best predicting unavailable states $(90 \%)$, but that predict availability less effectively (75\%). Our results, however, are the opposite. We seem to do well at predicting available states (95\% accuracy), but poorly at predicting unavailable states (61\% accuracy). Despite this significant difference, there are many lessons applicable to other CSCW environments.

\subsection{Personalization}

We have found context-mediated communication requirements are highly individual. In developing communication services, learning algorithms may be a good fit in developing personalized clients. While we have shown the significance of individual preferences within the home, other studies have developed similar personas using probabilistic models based on the individual's reported meeting attendance [30]. The relative degree of segmentation or integration of an individual's various commitments, both within and outside the home, provide differing, yet visible indicators for personalization [21]. For instance, when an individual bounds their parent role within certain times in the home, availability will differ accordingly. Although this study looks at home life activities as predictors of availability, these may serve as a baseline for similar explorations of availability in a wider variety of work settings, such as mobile work.

Within the home, we can envision adaptive interfaces that evolve an initial set-up of the service over time as the availability factors change. There are factors to availability that will need to be adapted to the individual household, such as recognizing transitions between availability states: changing rooms, preparing to leave home, or cleaning-up after a meal. Over weeks or months, the home life schedule changes to accommodate different sport team practice times, school year activities and other variations to the general schedule of in- and out-of-home activities. Will these factors correlate across the family members of the household? Must the service only be personalized by the individual within family group? Further research is needed to explore these questions.

\subsection{Activity Recognition}

There is a lot of interest in automated forms of activity recognition by researchers in ubiquitous computing and computational perception. This is a challenging problem from intellectual, engineering, and social perspectives. One of our motivations for this work is to determine if there are any externally observable factors in a home environment that correlate to self-reported availability. If such factors exist, then we can focus sensing and perception techniques at predicting those factors, either in real-time or over some time-relevant time interval.

The evidence we can glean from our preliminary study suggests that it may be most useful to target sensing to particular locations in the home, most notably in and around the kitchen, and toward particular activities, specifically face-to-face conversations. In separate work, we have begun to explore practical ways to detect face-to-face conversations using arrays of microphones that track the location of sounds in an environment without recording the sound [3]. Some leisure activities, such as watching TV or listening to music, both of which correlated to availability, can also be detected by the signature of sound patterns in the home. Other activities of significance, like reading, would not be amenable to this form of sound sensing.

What is important to stress from this work is the potential for detecting patterns of activities. Though our data analysis does not bear this out yet, interviews suggested that transitions between activities link better to being unavailable than the particular activities themselves. Transitional activities provide mental bridges between our social roles, as parent, friend, or chef [21]. One subject described how they were not available:

“... and that (refers to start of another activity with one child) gives us a chance to go out and do some errands. I don't know exactly, but we're either on our way to go out. I might have been getting [the other child] ready or something like that."

If the triggers to change mentalities and accessibility could be better established empirically, it would provide further motivation for the inherently statistical approaches to activity recognition that might be better at detecting boundaries between changing activities than at identifying specific activities.

\subsection{Social Construction of Interruption}

Over and over, the literature on conversational initiation highlights the social construction of interruption [12, 13]. Previous research conducted primarily in work environments suggests that individuals tend toward unavailability (perhaps because they are constantly dealing with the previous interruption) [13]. This study, however, suggests that individuals in home environments tend toward availability. One of the most important criteria for being a "good" parent, child, sibling, or friend is to be always accessible [33]. More significantly, social closeness between the individuals is the most important factor determining when one is accessible [33]. This suggests that social contexts play an important role for determining receptivity to interruption.

The social construction of interruption might help explain one anomalous finding in our data. In our ESM surveys, we asked subjects to indicate their availability to both an urgent interruption and a casual interruption. Follow-up regression analyses on each of these variables indicated our measure for a child's bedtime routine strongly predicted unavailability in the 
urgent condition, but had no significance in the casual condition. Why should we find that subjects are less available to urgent interruptions than casual interruptions? We hypothesize that this has to do with the degree of interruption implied by each. Urgent interruptions imply a full interruption where participants must drop everything. Casual interruption suggests partial interruption where subjects could continue preparing the child for bed while dealing with the interruption. Further research is needed to explore this hypothesis.

Social construction of parenting roles also plays a role in one's accessibility. In a two-parent household, how much a person is directly responsible for care of a child affects availability. The primary caregiver role may alternate between the parents or assumed by only one:

"[My spouse] and I take shifts, so what we do is I'm responsible for bathing [our child], well playing with her before..."

When in secondary parenting role, there is almost no impact on mentally switching roles for availability [21]. Parents' availability is also affected by how much attention they believe a child needs. When a parent provides more care, either as primary or from their view of the child's needs, there is less accessibility, due to the mental cost of this devotion to child [21]. The varying roles of parent within home life may provide availability cues through visible actions or as household rituals identified, by family or technology. Further research is needed into the social construction of interruption so that we as designers may better understand how to design appropriately flexible technologies for dealing with the challenges of interruption.

\subsection{Privacy}

Like most interruption studies, this work raises more privacy concerns than it addresses. What happens when sensors are placed throughout the home? Will individuals be comfortable knowing their behavior at home is being monitored? How comfortable will household members feel sharing availability information with close family and friends? How do we design open systems so those monitored understand what is happening?

As we move from examining office settings to studying the home, these questions become more acute. The home is our personal space, and we expect to have more control over our accessibility than outside it [33]. Privacy may be viewed as resolving the discord between the person and their conflicting social roles. Even within the context of our study, some participants raised fears over who would have access to their responses. As a research community, we must answer many questions about privacy as we attempt to develop technology to ease the problems of interruption.

\subsection{Future Research}

We intend to apply these findings to the design of communication technology enabling the family to select better times for conversation. For instance, interview data suggest the desire not to avoid an interruption, but rather to delay the interruption until a more suitable time. For example, one participant reported completing the survey as not available, only to be disturbed a moment later when interrupted by someone. Her instinctive response was, "Didn't I just tell you I'm NOT available now?" She wanted the system to understand that her responses indicated that interruption should be delayed by some amount of time. This ability to delay the interruption was mentioned in connection with returning or leaving the home and other home routines, such as bedtime. A prototype "delay interruption" service - similar to a "snooze button" on an alarm clock-would enable exploration of how family members manage interruption at home.

\section{CONCLUSION}

In this study, we explored various factors in the home that might be useful for signaling availability to close friends and family. Our results differed from similar office-based studies where knowing that someone is talking is the strongest predictor of when not to interrupt [14]. For the home, our study indicates a complex set of factors influence availability. We investigated three dimensions of observable factors: copresence, location, and activity. Copresence looked at the effects of being alone or with others, and revealed that subjects were less likely to be available when alone. Roomlevel location indicates the highest likelihood of being available in and around the kitchen. We considered twenty different activities and found five with significant correlation (positive or negative) to availability (engaging in face-to-face conversation, watching TV or movies, playing games, managing personal/family information, and engaging in miscellaneous leisure activities) and four more that warrant further study (reading and writing email, engaging in miscellaneous food activities, reading, and doing laundry/housekeeping). Our analysis suggests all three dimensions - who, what, and where - contribute to determining interruptibility. We have found office studies provide a reference point, but that home life studies differ in the level and type of individual personalization required, the significance of given activities, and the social construction of those activities.

\section{ACKNOWLEDGMENTS}

We especially thank the busy families that agreed to allow us to interrupt their home life for this study. Our thanks to Intel Research for the iESP software, Dr. Lisa Feldman Barrett and Daniel Barrett of Boston College for the original ESP software. Thanks to Dr. Amy Bruckman, our research group, and our reviewers for providing many insightful comments.

\section{REFERENCES}

[1] Beebe, S.A., Beebe, S. J., and Redmond, M. V. (1996). Interpersonal Communication: Relating to Others, Allyn \& Bacon, Needham Heights, MA.

[2] Begole, J., Tang, J., Smith, R. and Yankelovich, N. (2002). "Exploring work rhythm awareness: Coordinating contact among colleagues." Proceedings of CSCW'02. ACM Press, pp. 334-343.

[3] Bian, Zuehai, Abowd, G., and Rehg, J. (2004). "Using Sound Source Localization to Monitor and Infer Activities in the Home." Georgia Institute of Technology, GVU Center Technical Report, GIT-GVU-04-20. 
[4] Brown, A. L. (1992). "Design Experiments: Theoretical and Methodological Challenges in Creating Complex Interventions in Classroom Settings." The Journal of the Learning Sciences, 2(2), pp. 141-178.

[5] Consolvo, S., and Walker, M. (2003). "Using the Experience Sampling Method to Evaluate Ubicomp Applications." IEEE Pervasive Computing Mobile and Ubiquitous Systems: The Human Experience, 2(2), pp. 2431.

[6] Corbin, J. M., and Strauss, A. L. (1998). Basics of Qualitative Research : Techniques and Procedures for Developing Grounded Theory (2nd ed.). Thousand Oaks, CA: Sage Publications.

[7] Crabtree, A., Rodden, T., Hemmings, T., and Benford, S. (2003) "Tools for Studying Behavior and Technology in Natural Settings." Proceedings of UbiComp 2003, LNCS 2864, Springer, pp. 208-226.

[8] Czerwinski ,M., Horvitz, E. and Wilhite, S. (2004). "A diary study of task switching and interruptions." Proceedings of Conference on Human Factors in Computing. ACM Press, pp. 175-182.

[9] Geertz, C. (1973). Thick Description: Towards an Interpretive Theory of Culture. In Interpretation of Cultures. USA: Basic Books.

[10] Glesne, C., and Peshkin, A. (1992). Becoming Qualitative Researchers: An Introduction. White Plains, N.Y.: Longman.

[11] Hindus, D., Mainwaring,S. D., Leduc, N., Hagström, A. E., and Bayley, O. (2001). "Casablanca: Designing Social Communication Devices For The Home." Proceedings of the Conference on Human Factors and Computing Systems, ACM Press, pp. 325-332.

[12] Horvitz E., Kadie C., Paek T. and Hovel D. (2003). "Models Of Attention In Computing And Communication: From Principles To Applications." Communications of ACM, 46 (3), 52-59.

[13] Hudson, J.M., Christensen, J., Kellogg, W.A., and Erickson, T. (2002). "'I'd be Overwhelmed, But It's Just One More Thing to Do:' Availability and Interruption in Research Management", Proceedings of the Conference on Human Factors and Computing Systems, ACM Press, pp. 97-104.

[14] Hudson, S.E., Fogarty, J., Atkeson, C.G., Forlizzi, J., Kiesler, S., Lee, J.C., and Yang, J. (2003). "Predicting Human Interruptibility with Sensors: A Wizard of $\mathrm{Oz}$ Feasibility Study," Proceedings of the Conference on Human Factors and Computing Systems, ACM Press, pp.257-264.

[15] Intille, S.S., Tapia, E.M., Rondoni, J., Beaudin, J., Kukla, C., Agarwal, S., Bao, L., and Larson, K. (2003). "Tools for Studying Behavior and Technology in Natural Settings." UbiComp 2003, LNCS 2864, Springer, pp. 157174.

[16] Lacohee, H. and Anderson, B. (2001). "Interacting with the Telephone." International Journal of Human Computer Studies. 54(5): p. 665-699.
[17] Kubey, R.W. and Czikszentmihalyi, M. (1990). Television and the Quality of Life: How Viewing Shapes Everyday Experience. Lawrence Erlbaum, Hillsdale, NJ.

[18] McFarlane D. C. (1999). "Coordinating the interruption of people in human-computer interaction." Proceedings of Human-Computer Interaction (INTERACT'99), IOS Press, IFIP, pp. 295-303.

[19] Milewski A. E. and Smith T. M. (2000). "Providing presence cues to telephone users." Proceedings of CSCW '00, ACM Press, pp. 89-96.

[20] Nagel, K., Kidd, C., O'Connell, T., Dey, A. and Abowd, G. (2001). "The Family Intercom: Developing a ContextAware Audio Communication System." Proceedings of Ubicomp 2001, Springer, pp. 176-183.

[21] Nippert-Eng, C. E. (1996). Home and Work, Negotiating Boundaries through Everyday Life. Chicago, University of Chicago Press.

[22] O'Conaill B. and Frohlich D. (1995). "Timespace in the workplace: Dealing with interruptions." Proceedings of Human Factors in Computing Systems: CHI'95 Companion, ACM Press, pp. 262-263.

[23] Palen, L and Salzman, M. (2002). "Voice-Mail Diary studies for Naturalistic Data Capture under Mobile Conditions." Proceedings of CSCW'02. ACM Press, pp. 887-95.

[24] Panko, R.R. (1992). Managerial Communication Patterns. Journal of Organizational Computing, 2(1). pp. 95-122.

[25] Radway, J. (1991). The Act of Reading the Romance. In Reading the Romance. The University of N. Carolina Press, pp. 86-118.

[26] Reddy, M. and Dourish, P. (2002). "A Finger On The Pulse: Temporal Rhythms And Information Seeking In Medical Work." Proceedings of CSCW'02. ACM Press, pp. 344-353.

[27] Seidman, I. (1991). Interviewing as Qualitative Research. New York: Teacher's College Press.

[28] Sproull, L.S. (1984). "The Nature of Managerial Attention." Advances in Information Processing in Organizations, 1, pp. 9-27.

[29] Stinson , L. (1999). "Measuring How People Spend Their Time: A Time-Use Survey Design." Monthly Labor Review, August, 1999, pp. 12-19.

[30] Tullio, J., Goecks, J., Mynatt, E., and Nguyen, D. (2002). "Augmenting Shared Personal Calendars." Proceedings of the ACM Symposium on User Interface Software and Technology (UIST). ACM Press, pp. 11-20.

[31] Venkatesh, A. (1986). "Computers and Other Interactive Technologies for the Home." Communications of the ACM, 39 (12), pp. 47-54.

[32] Whitley, B. E. (2002). Principles of Research in Behavioral Science (2nd ed.). New York, NY: McGraw Hill.

[33] Zerubavel, E. (1985). Hidden Rhythms: Schedules and Calendars in Social Life. CA, USA, University of California Press. 